\title{
DAS (IM)POSSIBILIDADES DO CORPO: UMA ANÁLISE DISCURSIVA DA MODA SOBRE O CORPO PLUS SIZE
}

\section{OF THE (IM)POSSIBILITIES OF THE BODY: A DISCURSIVE ANALYSIS OF FASHION ABOUT THE PLUS SIZE BODY}

\author{
Pâmela Tavares de Carvalho* \\ Luciana Carmona Garcia Manzano"*
}

\begin{abstract}
Resumo: O presente trabalho propõe, a partir do método arquegenealógico engendrado por Michel Foucault, observar a moda como uma fabricação histórica que incide sobre os corpos e, mais especialmente, sobre o corpo gordo. De início, contextualizar-se-ão as mais imediatas manifestações de poder que, atravessadas pelo corpo, pela história e pela moda, produzem o próprio sujeito. Em seguida, procuramos demonstrar como o corpo tem sido aquilo pelo que se luta em diferentes momentos históricos. O conceito de dispositivo é tomado como ponto central na investigação dos indícios deixados na superfície histórica do discurso da moda na sociedade moderna. O material para o qual se volta nosso olhar analítico, na composição deste texto, é formado de duas publicações da revista Moda Moldes Especial Plus Size, que se inscrevem em um conjunto de práticas modelares sobre o corpo, colocando em discussão os modos de subjetivação da mulher gorda no espaço da moda.
\end{abstract}

Palavras-chave: Dispositivo; Moda; Corpo.

ABSTRACT: The present work proposes, based on the archegenealogical method devised by Michel Foucault, to observe fashion as a historical fabrication that affects bodies and, more especially, fat bodies. Initially, we will contextualize the most immediate manifestations of power that, crossed by the body, history and fashion, produce the subject himself/herself. Then, we try to demonstrate how the body has been what it is fighting for at different historical moments. The concept of device is taken as a central point in the investigation of the evidence left on the historical surface of the fashion discourse in modern society. The material to which our analytical gaze is

\footnotetext{
"Doutoranda do programa de Pós-graduação em Linguística pela Universidade de Franca (UNIFRAN). Servidora do Instituto Federal de Educação, Ciência e Tecnologia do Sul de Minas Gerais (IFSULDEMINAS). E-mail: pamela.carvalho@ ifsuldeminas.edu.br.

" Doutora em Linguística pela Universidade Federal de São Carlos (UFSCar), docente e coordenadora do Programa de Pós-graduação em Linguística da Universidade de Franca (UNIFRAN). E-mail: lcgmanzano@gmail.com.
} 
directed, in the composition of this text, consists of two publications from the Moda Moldes Especial Plus Size magazine, which are part of a set of model practices on the body, putting into question the modes of subjectification of the fat woman in the fashion space.

KeYwords: Device; Fashion; Body.

\section{INTRODUÇÃo}

O corpo, palco de (im)possibilidades, metáfora, discurso, terreno do desejo, ponto de suplícios e vítima das punições. A moda, reflexo do desejo no retrovisor do tempo.

Assim como se modificam historicamente as condições de produção social, política e econômica dos corpos, mudam-se de forma igualmente histórica as premissas de sua estetização. O corpo pode ser considerado como parte de um projeto social que, marcado nas suas transformações pelas vertentes sócio-culturais como a moda, traduz-se na sua normalização e na comercialização como um objeto rentável e que, como manifestação identitária do sujeito flexível e moldável, pode ser (re)modelado, manipulado e gerenciado no interior de saberes e poderes que lhe impõem proibições e obrigações, ou seja, de práticas disciplinares a partir de um conjunto de códigos, normas e valores culturais partilhados no âmbito social.

Seguindo esta premissa, o corpo é o lugar onde coabitam diversas concepções, haja vista a imagem da normalização, seja dos gestos, posturas, hábitos, vício ou expressões engendradas no imaginário cultural, seja da sua própria forma e/ou aparência. Desse modo, o corpo se desnaturaliza ao entrar em cena e se torna inteiramente marcado pela moda e seus discursos, os quais valorizaram/valorizam, no decorrer da história, formas e padrões que eles mesmos (re)criam.

A moda, entendida como um sistema de saber/poder amplo e complexo para além dos termos roupas e acessórios, espelha, traduz e altera, por processos de subjetivação, a percepção do indivíduo acerca do corpo que lhe envolve. Portanto, é na relação moda e corpo que aqui traçamos um caminho, dentre tantos outros possíveis, lançando nosso olhar para o discurso da moda e observando os jogos discursivos que o inscrevem historicamente em uma rede de sentidos, atravessados pelas relações de saber/poder e ancorados na moda enquanto dispositivo de controle, cerceamento e disciplina do corpo feminino rotulado como gordo.

Logo, neste artigo, ${ }^{1}$ buscamos trabalhar analiticamente a materialidade das capas da revista Moda Moldes Especial Plus Size dos meses de abril e dezembro do ano de 2016, magazine

\footnotetext{
${ }^{1}$ O presente trabalho, desenvolvido a partir da pesquisa de Mestrado realizada no Programa de Pós-graduação em Linguística na Universidade de Franca (UNIFRAN) sob a orientação da Prof. ${ }^{a}$ Dr. ${ }^{2}$ Luciana Carmona Garcia Manzano, deu-se com o apoio do Instituto Federal de Educação, Ciência e Tecnologia do Sul de Minas Gerais (IFSULDEMINAS), assim como da Coordenação de Aperfeiçoamento de Pessoal de Nível Superior (CAPES) -Brasil.
} 
editado e comercializado pela editora OnLine. Tomamos a moda, por meio dessa revista, como materialidade discursiva, porque traz à tona um corpo considerado, historicamente, anormal, desviante, o corpo gordo. Bordejamos esse discurso e sobre esse corpo poroso, que se mostra e se esconde, ao mesmo tempo, bordamos nossos traços, nossos gestos de interpretação. Nosso objetivo é, portanto, descrever, pautado em uma analítica do discurso de cunho foucaultiana, o funcionamento discursivo da moda a partir de enunciados que foram efetivamente ditos nas costuras das práticas cotidianas, constituindo meios disciplinares e de governamentalidade, a autorizar, ou não, visibilidades e dizibilidades desse corpo feminino que rompe com aquele estabilizado como normal, o magro e longilíneo, costumeiramente trabalhado pelo setor.

\section{(A)BORDANDO CORPO, MODA E HISTÓRIA}

À luz de Michel Foucault (2009), para que se possa compreender a produção dos discursos sobre o corpo imersa nas relações de poder que compõem tecnologias políticas e históricas, retomar-se-ão, em um breve movimento histórico, as práticas disciplinares que se consolidaram a partir do século XVIII, para que, posteriormente, possamos fazer uso da noção de dispositivo, uma ferramenta teórico-metodológica, na tentativa de apreender os mecanismos discursivos do universo da moda acerca do corpo rotulado pelo outro e para o outro como gordo.

Do suplício à punição, da prisão à disciplina, início para a formação e educação de uma vida em sociedade. Na Era Clássica, período entre o século XVI e XVIII, o governo da razão do soberano determina, pelo suplício, a arte de governar em que, sobre o corpo, limite para toda a afecção, é colocado todo o investimento político para a afirmação e demonstração de uma soberania por meio da barbárie do castigo e da presença contínua da morte como objeto de um teatro popular a marcar, na memória social, o enfrentamento entre o poder do rei e a afronta daquele que suas leis violou.

O suplício é a dissimetria da força e do poder ao reconstituir a integridade do corpo soberano. Sobre o talhe do condenado, marca-se, portanto, a representação e a visibilidade de um poder que perpassa a história do corpo, como a história do Estado e da moda.

Na dinâmica histórica, com o surgimento do Estado e o desenrolar das conquistas, os movimentos de importação, assim como o desenvolvimento comercial e urbano, a partir do século XIV, desestabilizam, por vezes, os usos e costumes de um corpo social de caráter estático e coletivista que, de uma sociedade fechada para uma aberta às influências externas, abandona os trajes até então concebidos para manter-se por tempos a fio para, agora, fixarem os olhares no rei e seus senhores. Com o avanço do mercantilismo e das grandes expedições marítimas, à sociedade foram apresentados novos produtos e especiarias, o que motivou a ascensão da moda. Nesse período, há, portanto, as primeiras manifestações da moda, quando os nobres eram caracterizados pelo luxo excessivo e marcados pelo consumo ostentatório. Contudo, com o surgimento de uma nova classe social, a burguesia, o vestuário já não é aceito de geração em 
geração, já não mais pertence à "memória coletiva" e, sim, torna-se o "reflexo das predileções dos soberanos", os quais, por sua vez, eram considerados, essencialmente, os portadores do indumento (LIPOVETSKY, 2009). É o início da Era da Moda, que tem, nos instrumentos do poder, a base para a sua existência.

Na cronologia da história, já no século das Luzes, o corpo supliciado é escamoteado. Entra-se no tempo da sobriedade punitiva, passa-se do suplício para a restrição de direitos e liberdade como elemento constitutivo da pena aplicada ao fato praticado. Nesse contexto de reforma penal, frente à efervescência e à estruturação do capitalismo, a nova teoria jurídica da penalidade visa, ao fazer da punição e da repressão das ilegalidades, a uma função regular, com universalidade e eficácia, co-extensiva à sociedade, logo não para apagar o crime, mas para transformar um culpado enquadrando seus gestos, suas condutas por meio de um sistema de autoridade e de saber (FOUCAULT, 2009).

Nasce, assim, a prisão, que, por sua vez, transforma-se em uma nova mecânica do poder, uma forma de dominação por meio da disciplina, que, em sintonia com a nova lógica econômica capitalista, explora, adestra, desarticula e recompõe o corpo, em um sistema de controle e vigília, na tentativa de gerar uma transformação do indivíduo pelo isolamento e trabalho.

Para além das mutações formais no direito e nas ferramentas de correção social, essa nova economia política sobre o corpo junto às instituições disciplinares define-se, também, no plano da narrativa da moda em que se desvanecem as marcas do suplício e surgem os uniformes, a evidenciar e marcar, no corpo confinado, o pertencimento a um grupo social, o controle político e a disciplinarização sobre o indivíduo. Os marginais, os criminosos, os devedores eram, então, separados, marginalizados pelas vestes horizontalmente listradas, padronagem essa que trazia em seu sentido social o status negativo por causar, no outro, certa perturbação no olhar. É o vestuário, segundo Calanca (2011, p. 25), como "máscara social" de identificação, como documento e espelho que reflete estruturas e práticas em corpo "que se treina, que obedece, responde, se torna hábil ou cujas forças se multiplicam" em um estado de permanente e consciente observação (FOUCAULT, 2009, p. 163).

Se, no limiar entre os séculos XVII e XVIII, o corpo e a vida formam o cerne para o exercício da disciplina, pelos operadores de dominação que caracterizam as políticas do corpo, e a formação do biopoder, no início do século XX, com uma intensificação das disciplinas, da sociedade disciplinar para a sociedade de controle, é decisiva a noção de governo, que se exerce, concomitantemente, sobre a individualidade e o corpo social, que, ativos e livres, possibilitam pelo direito a ação do poder sobre si para guiá-los, dirigi-los, governá-los, uma vez que só haverá poder onde houver liberdade.

Numa racionalidade política individualizante e totalizante, a governamentalidade apresenta-se como um conjunto heterogêneo de saberes delineados por instituições, procedimentos, análises e táticas que permitem exercer a forma específica e complexa do poder que tem, por objetivo principal, a população e que se denomina, por meio da economia política e dos 
dispositivos de segurança, o governo de si sobre todos os outros. Desse modo, como resultado do processo de mutação do Estado de justiça da Idade Média para o Estado administrativo, trocam-se as virtudes tradicionais como a sabedoria, a justiça, o respeito a Deus etc., por uma nova arte de governar que implica não só uma gestão populacional, mas um controle das estratégias que os indivíduos, na sua liberdade, possuem em relação a eles mesmos e uns com relação aos outros. Nesse sentido, ao observar as formas de governo do corpo relacionadas à moda, é possível atentarmos que não basta apenas a ação de instituições ou mesmo mecanismos de outra ordem, é preciso chamar "o sujeito a colaborar em seu próprio governo, pois os valores que influenciam como somos governados devem coincidir com aqueles que moldam a forma como governamos a nós mesmos" (NETLETON, 1997, p. 214 apud MENDES, 2006, p. 177).

Controle e não apenas disciplina. A crise das instituições junto a seus instrumentos de reclusão e a instalação de novas forças, que se anunciam num inevitável processo histórico, levam o regime disciplinar a deslizar-se do âmbito local, de um sistema fechado e restrito à extensão dos olhos, para o espaço da vida pública. Estamos, pois, a entrar na sociedade de controle, "que [funciona] não mais [pelo cárcere], mas por controle contínuo e comunicação instantânea” (DELEUZE, 2010, p. 219).

Nesse contexto, com uma intensificação da disciplina, a sociedade de controle faz, no corpo, o alvo para a produção de subjetividades, que, em constante transformação, encontrar-se-ão não mais fixadas na individualidade e na passarela da mídia, como a moda e o estilo de vida, mas em um sistema de visibilidades que corrobora uma ortopedia social ao incitar a interiorização e a incorporação de convenções e normas idealmente construídas. Por isso, afirma Foucault (1998, p. 148): “O corpo se tornou aquilo que se está em jogo [...] encontramos novo investimento que não tem mais a forma de controle-repressão, mas de controle-estimulação: Fique nu... mas seja magro, bonito, bronzeado!".

E aqui, ao refletirmos sobre o poder como foi proposto por Foucault (1998) e concebendo-o a partir de um contexto social e político, torna-se possível estabelecer, assim, uma relação entre as noções de poder e moda.

Por tempos, a moda fora um instrumento de distinção e poder. Por meio do vestuário, os indivíduos se diferenciavam dos outros exercitando, globalmente, a hierarquia das condições (LIPOVETSKY, 2009). A roupa funcionava como insígnia do poder daquele que a portava no meio social em que estava inserido; no entanto, a moda não se deleitava apenas com um signo de condição de classe e de país, mas ditava o que, como e onde a roupa deveria ser usada, desaguando, pelas correntezas de décadas e séculos, nos manuais e revistas de estilos, que, por sua vez, sugerem ao consumidor e/ou leitor a imagem a adotar dentro do que é legitimado como correto.

O corpo, portanto, está na moda, e esta, sob a lógica que perpassa a sociedade moderna, encontra nas esferas da vida social o âmbito para a ascensão e fixação do seu império. Consolidada na modernidade, em um cenário de redefinições de tempo e espaço que faz do 
viver uma metamorfose de informações, práticas sociais e formas de sociabilidade, a moda se entrelaça ao corpo, tornando-se elemento integrante no terreno de construção das subjetividades, e este, o corpo, como cerne principal da sociedade disciplinar e de controle e marcado por gestos, vestes e formas, não cessa de ser (re)fabricado como espelho do tempo, dos poderes e saberes.

Dessa maneira, a moda como um fenômeno moderno e das aparências, uma prótese do corpo, de corpos dóceis e úteis, como nos fala Foucault (2009), invade outras searas e se expande para além do vestir. A partir de saberes por ela produzidos, a moda torna-se um agenciador de subjetividades, produz e origina indivíduos que, diferente de outros tempos, nos quais eram avariados pelo suplício ou banidos em cárcere, são docilmente fabricados para que, então, tornem-se sujeitos e objetos de discurso, tal como eternos vigilantes do ser e do sentir.

Nessa direção, o corpo, no "tempo de imergir nas malhas do poder" (GREGOLIN, 2006, p. 103), que lhe impõem proibições e obrigações, faz-se a tela ideal para a auto-expressão e para os processos de subjetivação do sujeito, no qual, investido por uma série de esforços, sobretudo da mídia de moda, pode ser modelado e gerenciado, criando novos sentidos e necessidades e revelando padrões estéticos estabelecidos e intensificados por uma biopolítica que se repete sem cessar num entrelaçado de forças estrategicamente estabelecidas entre elementos heterogêneos.

\section{ENTRE SABER E PODER, O DISPOSITIVO}

A noção de dispositivo, da arqueologia à genealogia, porém, de modo correlato na ampliação do campo investigativo, surge em resposta às dificuldades descritivas na arqueologia, posicionando o saber no horizonte das relações de poder e das lutas políticas. Como uma ferramenta analítica na relação saber, poder e sujeito, o conceito foucaultiano compreende um conjunto de "discursos, instituições, estruturas arquitetônicas, regulamentos, leis, medidas administrativas, enunciados científicos, [...], o dito e o não dito, [...]" (FOUCAULT, 2011, p. 244). Trata-se de uma rede de elementos heterogêneos que responde, portanto, sob as múltiplas relações de poder e suas ações, a uma urgência histórica. Compreender esse movimento nos permite perceber, no processo de objetivação e subjetivação do sujeito necessário à sociedade de produção, a relação entre o indivíduo e os mecanismos de exercício do poder que se fazem presentes nos aglomerados das instituições.

Desse modo, do conceito genealógico engendrado por Foucault, podem-se apreender os seguintes pressupostos: (I) Há dispositivo desde que a relação entre elementos heterogêneos, linguísticos ou não linguísticos, concorra para produzir certo efeito de subjetivação no corpo social, seja ele de normalidade ou desvio; (II) O dispositivo oferece um novo território de verdades; (III) Como uma função estratégica dominante é sempre um investimento político do e no corpo; (IV) É dinâmico, dado que engloba o processo de sobredeterminação funcional 
(trata a forma como os efeitos produzidos por um dispositivo são rearticulados ao conjunto) - e de preenchimento estratégico (processo de recaptura daquilo que é colocado em suspenso na batalha agônica entre o dominante e os movimentos de resistência).

No contexto dessas questões, o dispositivo, por ser dinâmico e eficaz, produz fitos na coletividade, constitui sobre o sujeito saberes avantes de uma relação epistêmica, tal qual uma prática de subjetivação que institui modos de ser, de se comportar, de agir e até mesmo de se vestir. Isso posto, há, nos processos que constituem a subjetividade, uma vigência milenar que envolve os dispositivos de uma sociedade em que estamos, ainda, imersos, como se, em nosso tempo, repercutisse uma história dos processos pelos quais nos tornamos sujeitos.

Como solo da subjetivação, ao tratarmos o dispositivo e, certamente, o discurso que lhe é inerente e que toma a tudo e a todos, como tudo aquilo que, na urgência de um dado momento, adequa e subordina os saberes, ao mesmo tempo em que se adequa e se subordina aos mesmos, por meio das relações de poder, pode-se, então, dizer que saber, poder e verdade formam o tripé em que se sustentam os dispositivos.

No que diz respeito ao poder, Foucault (1998) rompe com as concepções clássicas do termo. Concebe-o não como algo localizado e que emana de uma instituição determinada ou do Estado, e sim do "governo" dos outros, no qual seu sentido está diretamente ligado à forma de conduzir os indivíduos de uma sociedade, pois seu exercício é agir sobre a probabilidade de ação dos sujeitos que, sejam eles individuais ou coletivos, distribuem-se em um espaço onde possibilidades de condutas, reações e modos de comportamento podem se realizar. Trata-se de ler o poder não como algo concentrado ou distribuído, mas como exercício de uns sobre outros que se concretiza nas ditas sociedades "de controle", marcadas pelos limites da modernidade, em que há uma máxima da normalização e disciplinaridade por meio dos mecanismos de comando distribuídos pelos corpos e cérebros dos indivíduos.

Com o estudo acerca do poder, Foucault (1998), então, apresenta um instrumento de análise capaz de explicar a produção dos saberes, como peças nas relações que constituem os dispositivos, estabelecendo uma ligação profunda e fundamental entre poder e saber. Não se trata, pois, de uma analítica geral do poder, mas este como uma prática social constituída historicamente, a partir da qual se pode observar a produção de saberes.

Dessa forma, ao analisar o lugar da formação dos saberes, a reflexão foucaultiana opera uma abordagem de um poder produtor de verdades, ou vontade de verdade, que ordena a sociedade. Sob essa explanação, tomando como problemática desta escrita a moda, o ato de vestir, assim como outros elementos culturais, são habilidades apreendidas, ou seja, é da ordem do saber, posto que se trata de um processo pelo qual o sujeito se modifica/é modificado durante a atividade de conhecer. Vestir-se, então, é uma prática que requer técnicas e, por isso, envolve normas culturais e expectativas em relação ao corpo (CASTRO, 2007), podendo, nesse sentido, ser entendido, para além de uma técnica corporal, como um saber que traceja, que situa e que determina formas de existência coletivas e/ou individuais. 
Alicerçado nos pressupostos até aqui apresentados, faz-se necessário observar que, da relação entre saber e poder, emergem subjetividades. Foucault (2011) estabelece a noção de um sujeito obediente, visto como uma realidade fabricada, que existe em muitas e diferentes modalizações, que é produzido e sustentado por um poder pouco notado e de difícil denúncia, ou seja, por um poder que circula por meio de pequenas técnicas tramadas em uma rede de instituições. Dessa forma, pensando o sujeito como construto do dispositivo, tem-se, então, um campo aberto aos processos de objetivação e, consequentemente, de subjetivação, marcados pelo poder/saber na constituição dos sujeitos. Em suma, o funcionamento desse maquinário de poder pode, assim, ser descrito: num determinado momento histórico, certo regime de verdade é produzido na emergência dos dispositivos de poder, que, por sua vez, amparados em saberes, objetiva e subjetiva os sujeitos para a obediência e proficuidade.

Para o caminho então proposto, acreditamos que a noção de dispositivo se apresenta, portanto, em um só tempo, como uma função metodológica, proposta para o acesso de determinados objetos na sua lida com práticas sociais e históricas, quanto como uma arena sobre a qual o investigador/analista atua como um desembaraçador das linhas entrelaçadas, percorrendo os pontos da tecelagem de um tecido na busca pelas possíveis irregularidades e fissuras entre a trama e o urdume.

Assim, analisar um dispositivo requer, daquele a que se propõe, dar luz à sua fabricação. Isto é, não em busca da derradeira verdade dos fatos, mas como um pirotécnico, que, a partir da composição de um roteiro baseado em elementos heterogêneos, compostos por enunciados, que são, conforme expressão foucaultiana, elementos discursivos e não discursivos, olha para as falhas, para as rupturas fora de um quadro de evidências consagrado pelas figuras tradicionais e logicamente estabilizadas. Analisar um dispositivo, nos dizeres de Albuquerque Júnior (2017, p. 7), é, portanto, "descrever as linhas que constituem uma dada configuração histórica, uma dada região das práticas, um dado domínio de objeto, um dado lugar de sujeito, [...] desenhando novas linhas de significação [...]".

Assim, das linhas que tecem a rede entre os elementos heterogêneos que constituem o dispositivo é que se pode perceber a emergência de um saber. Saber este que delimita as condições de possibilidade da irrupção de enunciados diversos no interior do dispositivo da moda, que, por sua vez, possui, como função estratégica, controlar e dominar pelo saber, no objetivo de atender e responder a uma urgência.

\section{O CORPO QUE FAL(H)A NA ORDEM DO DISCURSO DA MODA}

Observar a moda na perspectiva discursiva é apreender seu discurso como lugar de inscrição do acontecimento, é compreender que as condições de produção do seu discurso determinam as (im)possibilidades físicas e simbólicas do corpo ao longo da história. Sabe-se que a normatização e consequente padronização do corpo feminino é uma constante sujeita 
à evolução histórica. Nesse contexto, a moda, por meio de suas tecnologias de poder, ocupa um lugar notável de constituição, formulação e circulação de sentidos, afinal, ela, enquanto uma instituição de poder, ou melhor, um dispositivo de controle, determina o que pode e o que não pode ser dito e/ou visto em seus diferentes espaços, em cada instância de circulação.

Assim, acreditando ser o corpo seu suporte e orientação no terreno acidentado do discurso, tomamos como recorte para a análise que aqui segue os enunciados verbais e imagéticos, referentes a práticas apresentadas como valorização do corpo gordo, presentes nas capas das revistas Moda Moldes Especial Plus Size.

Figura 1 - Capa da Moda Moldes de abril de 2016
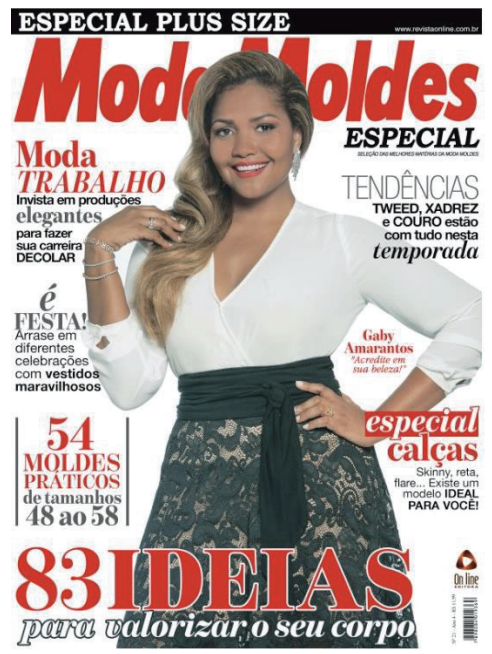

Fonte: Moda Moldes (2016)

Figura 2 - Capa da Moda Moldes de maio de 2010

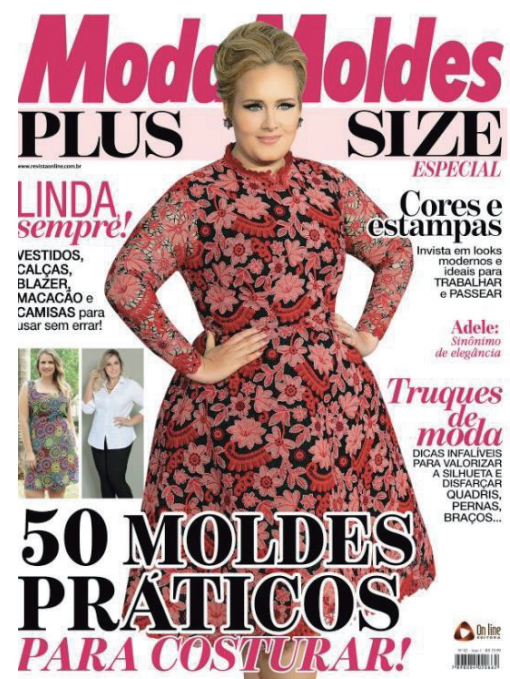

Fonte: Moda Moldes (2010) 
Ver e dizer. Olhar e falar. Enxergar e ler. Visibilidades e enunciabilidade que vão se combinando no dispositivo potencializado e operacionalizado nas capas acima em destaque, acionando, de modo veemente, o sujeito leitor mulher gorda a transformar, com atitudes de moda, o próprio corpo.

Do jogo entre elementos verbais e imagéticos, Especial plus size anuncia as chamadas das revistas, no espaço de suas capas. Frente à perspectiva foucaultiana de discurso, poderíamos questionar por que esse enunciado e não outro em seu lugar? Ao observamos as capas de forma panorâmica, das edições em análise, veiculadas nacionalmente no ano de 2016 e, também, comercializadas durante o ano de 2018 , as edições marcadas pelo enunciado "ESPECIAL PLUS SIZE", em forma e lugar de destaque junto ao nome da revista, Moda Moldes, um signo linguístico cujas iniciais encontram-se em linhas maiúsculas no centro superior da capa, revelam um outro tipo de público que não aquele para o qual, tradicionalmente, direciona-se a indústria da moda.

Ao apresentarem os volumes por meio da adjetivação especial, seguido pela nomeação plus size, as revistas, como sujeitos discursivos que constroem para si um lugar institucional de dizer legitimado, estabelecem um espaço social que autoriza, a esse corpo, dito e visto pelo olhar do outro como gordo, em contraposição àquele considerado magro, uma condição de existência e, ao posicioná-lo no discurso da moda, por meio da expressão plus size, permitem sua entrada em um campo do dizível, promovendo efeitos de sentido de um reconhecimento social vinculado ao acesso à moda. Um corpo incluso, que, na relação entre o imaginário e o simbólico, afirma ser o plus size não um gordo, mas sim uma nominalização para tamanhos maiores, (re)criando sentidos que deslocam o corpo acima do peso, o gordo, do lugar da feiura, do desmazelo, do atraso físico para a posição da beleza, da salubridade, do fashion.

Nesse deslizamento, o discurso se faz na tensão entre o mesmo e o diferente, entre algo que se mantém na memória e algo que se renova a cada enunciação. Assim, o termo plus size, resultado de um processo que o constitui em uma ordem discursiva, faz circular novos sentidos e estabelece, ao sujeito, uma nova posição social, já que "o sujeito do enunciado [...] é uma função vazia podendo ser preenchida por indivíduos até certo ponto indiferentes, ao formularem o enunciado" (FOUCAULT, 1987, p. 107).

A partir da compreensão de que há sempre batalhas discursivas na constituição de sentidos em uma sociedade, o vocábulo "especial", em um sistema de dizibilidades controlado por regimes de poder, joga, pois, com o efeito de positivo, circunda o corpo, discursivizado nas capas das revistas, como um mecanismo de proteção e valorização que atenua o estado de estigma, dado pelo adjetivo plus size, ao segregar o corpo e/ou o consumidor de moda, que, amalgamado por outras instâncias, como a publicidade, a medicina e o capitalismo, colabora "para regulamentar as diferenças e determinar padrões estéticos, em termos daquilo que é próprio e impróprio, adequado ou inadequado, normal ou anormal” (NOVAES, 2010, p. 34). 
Nesse contexto de produção enunciativa, a moda que emerge e se inscreve no espaço de ambas as edições das revistas, Moda Moldes Especial Plus Size, oferece ao sujeito-leitor mulher gorda um acordo entre pessoas, assim como entre o Estado e o cidadão (FOUCAULT, 2008), um pacto que, envolto à lógica "você lê, nós lhe falamos/mostramos o que e como fazer", instaura uma governamentalidade orientada por uma tecnologia de poder, a moda; por outro lado, um biopoder que atua sobre o corpo, sobre o detalhe, sobre o indivíduo, já que a este interessa a vida, a conduta, o modo de se portar, de se vestir. "É o momento em que a política se biologiza e a vida se politiza. É o tempo da biopolítica” (KATZ, 2011, p. 22), criando condições de possibilidades para que o corpo da mulher seja subjetivado pelo esquadrinhamento entre o gordo e o magro, o bonito e o feio, o manequim 38 e o 48, na moda e fora de moda.

Em primeiro plano, na figura 1, o enunciado, "83 ideias para valorizar o corpo", a destacar a principal chamada da revista, no contraste entre o quente da cor vermelha e o neutro da cor branca junto à saliência não só das cores, mas também do marcador de quantidade 83 -, assim como o enunciado "Truques de moda - dicas infalíveis para valorizar a silhueta e disfarçar quadris, pernas, braços...", presente na figura 2, guiam o olhar e a atenção daquela que se subjetiva gorda e opera na produção de um efeito de verdade, por um deslizamento de sentidos que vai opacificando a correção do corpo e reluzindo a estima, marcado pela recorrência do verbo valorizar, que amplia a associação entre gordo e feiura ao mesmo tempo em que colabora para a construção do saber sobre este, o gordo, na moda.

Ao estabelecer, no contrato de leitura, uma relação de finalidade, diz-se para esse leitor-sujeito aquilo de que ele necessita, valorizar o seu corpo, pois é preciso "disfarçar quadris, pernas, braços...”. A revista surge, então, como o elemento que o salva da lástima do peso, do conflito corpóreo. Alguém, na posse de um saber, enuncia para outro frente à urgência de um precisar saber e, nesse jogo, na tentativa de subjetivação, o sujeito, que ora se apropria do próprio corpo, ora é apropriado pelo outro, é chamado a assumir uma posição. Desse modo, é possível perceber um primeiro movimento enunciativo que objetiva e, consequentemente, subjetiva o sujeito-leitor, que, a partir de tal enunciado, passará a gerir suas escolhas em um efeito de autonomia, pois, onde há poder, há liberdade.

A utilização da palavra valorizar, nas duas edições, não só institui um deslocamento de efeitos de sentidos, como também produz novas possibilidades de objetivação e subjetivação. Às mulheres, cabem os valores eufóricos da beleza, do cuidado e da felicidade, assim como os disfóricos do desleixo, da feiura, da falta de cuidado, quando objetivadas em magras ou gordas. No entanto, o vocábulo valorizar joga com os verbos em modo imperativo no interior dos enunciados, "Invista em produções elegantes para fazer sua carreira DECOLAR", "Arrase em diferentes celebrações com vestidos maravilhosos", (figura 1), "Invista em looks modernos e ideais para TRABALHAR e PASSEAR" (figura 2), no processo de objetivação/ subjetivação, a fim de justificar as práticas a serem realizadas por um sujeito mulher gorda, possivelmente, insatisfeita com seu corpo, uma vez que esta é marginalizada em relação ao público consumidor 
de moda, evidenciando a exclusão em um movimento de inclusão (AGAMBEN, 2005), no qual a exceção serve somente para garantir a continuidade da regra universalizante, ou seja, é um modo de ser gorda na moda, logo, plus size, legitimando a hegemonia inconteste do corpo magro da e para a moda.

Valorizar - corrigir - o corpo, por meio dos saberes instituídos pela moda, é, então, o antídoto aos insultos de uma imagem corporal fora de ordem, que, certamente, produzirá objetivação e subjetivação no público feminino da revista, sob a ordem de uma biopolítica do corpo que age por meio de uma tecnologia do poder, normatizando a fabricação de sujeitos. Assim, antes de ser plus size, há um modo permitido de ser plus size.

Conforme Foucault (2008), formas de controle e dominação convocam o sujeito a lançar um olhar responsável sobre si, construindo as próprias verdades sobre o seu corpo, ora, já não é mais o Estado controlando o sujeito com suas biopolíticas, mas o próprio sujeito se responsabilizando por um equilíbrio numa eterna vigilância visual. A opulência das carnes e a magreza das formas torna-se a Via Crucis do corpo na contemporaneidade. Com isso, as estratégias do biopoder na imagem e no vestuário se disseminam, banalizam-se, naturalizam-se. A norma é internalizada, naturalizada e reproduzida, inclusive, pela ampla maioria dos profissionais de moda.

É, assim, instaurado o governo de si em que, na relação do sujeito-leitor com o corpo, subjazem os enunciados que dão voz ao espetáculo Moda Moldes: E1: "Invista em produções elegantes para fazer sua carreira DECOLAR." (figura 1); E2: "Arrase em diferentes celebrações com vestidos maravilhosos." (figura 1); E3: "Skinny, reta, flare... Existe um modelo IDEAL PARA VOCÊ." (figura 1); E4: "Truques de moda - dicas infalíveis para valorizar a silhueta disfarçar quadris, pernas, braços...” (figura 2); E5: “LINDA sempre!” (figura 2).

Observar as revistas como espaço de ação do dispositivo da moda nos leva a considerar que suas configurações enquanto produtos de consumo atuam na produção de sentidos. Isso posto, as expressões decolar, vestidos maravilhosos, ideal para você, disfarçar quadris, pernas, braços, linda, presentes nos enunciados, pelas capas das revistas, incidem sobre a otimização do corpo em termos de sistema de recompensas em vista de condutas almejadas, atribuem ao sujeito, no laço saber - poder, aspectos valorativos nas práticas de si, e estas, por sua vez, manter-se-ão ativas na subjetividade.

Esta, a subjetividade, torna-se, portanto, um direito à diferença, à mudança, que, acometida pela relação consigo mesmo, permite ao sujeito-leitor operar ações sobre seu corpo, por meio do vestuário, para se inscrever em um espaço fashionista que antes a ele era negado. Os sentidos se estabelecem em um processo gradativo de causas e consequências. Nesse âmbito, a moda transcende para uma experiência estética em que o corpo e as roupas conectam o sujeito a um mundo exterior a ele. Contudo, o controle, camuflado na recompensa oferecida, desemboca num saber que dá sustentação a um poder que se volta sobre o sujeito. Todavia, que saberes são esses próprios da moda que normatizam para normalizar, além de produções elegantes para 
conquistar sucesso profissional e os vestidos maravilhosos para arrasar nas festas, o modelo de calça ideal "Skinny, reta flare"... "Existe um modelo de calça IDEAL PARA VOCÊ", os "54/50 MOLDES PRÁTICOS de tamanhos 48 ao 58 ” e os "VESTIDOS, CALÇAS BLAZER, MACACÃO e CAMISAS para usar sem errar".

As formas de conhecimento expressas em representações sociais confirmam que, independente da época, as sociedades produzem verdades para controlar os movimentos, surpreendentes, do discurso. No que tange à moda, o saber, advindo das linhas de visibilidades e dizibilidades, parte de uma normatização, nos ordenamentos biopolíticos, ancorados a um saber científico, como a antropometria, para normalizar o que é ser gordo e o que é ser magro, o que é certo ou errado, o que e como se vestir, em suma, como apresentar os corpos sob a égide de um processo disciplinar.

Por entre os enunciados, que incidem diretamente na alfabetização normalizadora dos sujeitos, têm-se, à disposição daquele que deve ser dócil, logo, submisso, sessenta e seis páginas, em ambas as revistas, que integram um manual de estilo ocupado por um time de especialistas, consultores de estilos, modelistas, entre outros profissionais, que anunciam técnicas disciplinares acerca do que pode, o que deve e como vestir, afinal "ninguém entrará na ordem do discurso se não satisfazer a certas exigências ou se não for, de início, qualificado para fazê-lo" (FOUCAULT, 2000, p. 37). As revistas, portanto, midiatizam uma superprodução de saber que abarca as visibilidades enunciativas do corpo.

Nessa rede discursiva, ao marcar no enunciado a expressão "tamanhos 48 ao 58 " (figura 1), marca-se o corpo em um processo classificatório estabelecido pela normalização. Uma ação que permite que os sujeitos sejam esquadrinhados, individualizados, identificados e nomeados, por meio de um número correspondente a medidas corporais, por uma função especialista em uma racionalidade biopolítica.

As revistas, por meio da medida corporal, solidificada em tabelas e nomenclaturas como G (tam.48/50), GG (tam.52/54), EG (tam.56/58), atuam no detalhe da vida, nas linhas do corpo e na experiência do vestir-se, do modelar-se. Por conseguinte, ao enunciar a sequência "54 moldes práticos", “50 moldes práticos", sinalizando-a na urgência da cor vermelha (figura 1) e no negrito da cor preta (figura 2), em forma maiúscula e longilínea, as revistas lançam mão de tecnologias do controle de um corpo em metamorfose.

Ao mesmo tempo em que impinge ao sujeito-leitor, na ênfase pelo adjetivo prático, a responsabilidade e a "liberdade" para agir sobre as próprias formas, por meio dos recursos de modelagem que podem desfigurá-lo e colocá-lo dentro das perspectivas, da moda, que o desenham e o inscrevem como plus size, uma vez que é possível, por meio da representação bidimensional do vestuário, construir sobre o corpo "[...] formas diferenciadas cujo objetivo não seria só o de revesti-lo, mas também o de redesenhá-lo com [contornos diferenciados]" (MARIANO, 2011, p. 77). Nesse sentido, o adjetivo prático reforça a objetivação do(s) sujeito(s) 
mulher(es) gorda(s) como não consumidor de moda, assim como produz o efeito da necessidade do controle da vida por meio do controle sobre as vestes do próprio corpo.

Condicionados e regulamentados pelas relações de poder e saber, pelo social e histórico, os discursos das revistas, ao se apropriarem de outros discursos para legitimarem sua fala no dizer sobre o outro, constroem um espaço de autoridade, um lugar de saber a verdade sobre o corpo (im)possível na e para a moda. Caminhar entre as palavras e as imagens no folhear das laudas, possibilita-nos, pois, conhecer técnicas para um governo de si, as quais, ancoradas a uma biopolítica do corpo, transformam os sujeitos, possibilitando novas subjetividades no deslizar, pelo fio do discurso, do gordo para o plus size.

Na edição do mês de abril de 2016, o percurso de leitura, o olhar do interlocutor, é captado pela imagem do corpo da cantora Gaby Amarantos e, na sequência, é atraído pelos enunciados que instauram a promessa de sucesso, de felicidade, de consumo de moda. O corpo que aparece destaca-se pelo jogo entre o branco e o preto da roupa e pela acentuação da cintura, tanto pela faixa quanto pelos vetores formados na orientação do decote e do cabelo colocado sobre os ombros. Podemos dizer que o sentido do sucesso corporal do ser plus size se edifica nesse modelo de corpo e de silhueta; porque, primeiramente, apresenta-se o corpo vestido segundo as normas da moda para, na sequência, enunciar as obrigações para se alcançar o espaço mostrado pelo corpo, a moda. Aqui temos, portanto, um corpo plus size espetacularizado, que, ao ser usado para ilustrar o sucesso daquele que se subjetivou a uma valoração corporal pela moda, torna-se um corpo referência, ou seja, o interlocutor é persuadido não somente pelas técnicas em si, mas também pela vontade de possuir esse determinado corpo.

Apenas oito meses separam a edição estrelada pela cantora Gaby Amarantos da edição publicitada pela cantora americana Adele, na qual a situação se repete. No percurso de leitura da edição de dezembro de 2016, o sujeito interlocutor é atraído mais uma vez pela imagem do corpo em destaque, que dá a ver, pela roupa e pelo arranjo dos braços e das mãos, uma ênfase na cintura. O enunciado, posicionado em destaque à esquerda da imagem, afirma "Linda Sempre", produzindo o sentido de que a mulher que investe em peças de roupas ideais e que usa truques para corrigir a silhueta é como aquela que ilustra a capa: plus size, logo, consumidora de moda.

Assim, o corpo é invadido e guiado pelas narrativas midiáticas da moda que, sob a égide de uma vontade de verdade, esquadrinham e modelam as formas, determinando o que pode e o que não pode ser dito e/ou visto em seus diferentes espaços, em cada instância de circulação. Aqui, no tocante às estratégias discursivas postas em ação no espaço da revista Moda Moldes Especial Plus Size, edição ${ }^{\circ} 21$, ano 2016 (figura 1), e edição nº 02, ano 2010 (figura 2), por meio do conjunto enunciativo do texto sincrético, a moda em sua teia de docilização disseca o corpo com régua e compasso, e este, distribuído no eixo vertical e horizontal, penetra em retas, curvas, diagonais e perpendiculares no terreno de construção da objetivação/subjetivação do sujeito-mulher gorda. 
Em um espaço promocional, a moda, ao normatizar e fazer circular, por meio de práticas discursivas, uma forma corporal emergente, pela nomeação plus size, age como um preenchimento estratégico do dispositivo da moda, pautado na lógica de mercado e consumo para o estabelecer das fronteiras de modelação, determinando espaços de pertencimento, assim como espaços de exclusão: ora, não é qualquer corpo que pode e/ou deve ser mostrado, nem todo gordo pode ser plus size.

Assim, percorrido esse caminho, pôde-se observar o dispositivo da moda na sua mais intensa e máxima expressão, no qual as linhas de visibilidade e enunciabilidade operam nas malhas do próprio dispositivo, incidindo sobre o sujeito em processo de objetivação e subjetivação. Não obstante, é ainda preciso acentuar que o dispositivo permanece, pois se abre para um duplo processo, o de (I) sobredeterminação funcional e de (II) perpétuo preenchimento estratégico, a partir dos quais possibilita a emergência de novas estratégias, capazes de ultrapassar as amarras do saberes e poderes constituintes do próprio dispositivo.

Sobre o primeiro, para uma coerência interna entre os elementos heterogêneos em benefício da estratégia implementada, requer-se uma mudança interna, um reajuste na forma pela qual os elementos se vinculam. De outra forma, tem-se que "cada efeito positivo ou negativo sobre o objetivo estratégico vem entrar em ressonância ou contradição, produzindo ajustes nos elementos heterogêneos" (SARGENTINI, 2015, p. 23).

Por outro lado, esta definição funcional não é fixa, e sim passível de se transformar no tempo à luz das práticas e dos campos de saber aos quais o dispositivo está ancorado. Posto isso, o segundo processo que contribui na consolidação do dispositivo é o de perpétuo preenchimento estratégico, por meio do qual seus elementos renovam continuamente as funções estratégicas. Isto é, a reutilização dos efeitos involuntários e negativos do dispositivo em uma nova estratégia, que, de certa forma, ocupa o espaço vazio ou transforma o negativo em positivo. A propósito, essa renovação pode ser intencional ou mesmo consequência de nova configuração das práticas estratégicas.

O preenchimento estratégico não se caracteriza, portanto, por um controle absoluto do outro sobre as suas práticas ou sobre os campos de saber, visto que o poder pode se voltar contra ele mesmo. O fato de sua renovação ser perpétua aponta que o preenchimento se dá de forma autônoma e incerta, podendo os resultados alcançados divergirem da proposta estratégica inicial. Desse modo, o processo de perpétuo preenchimento estratégico abre a possibilidade de integrar elementos a priori não desejados no dispositivo. Um exemplo é o efeito de pertencimento de determinados corpos que a moda passou a produzir com o estabelecer do termo plus size, cuja estratégia original explícita, pautada numa razão mercantilista, visa à correção do corpo por meio de produtos de moda.

Frente às reflexões aqui tecidas, reconhecemos, tanto teórica quanto metodologicamente, o quão necessária nos é a noção foucaultiana de dispositivo, pois, por ela, podemos expandir o domínio das análises desenvolvidas em nosso estudo, lidando não com uma estrutura 
fechada, organizada, cujos elementos estão previamente dados, mas, antes, com aquilo que é da ordem do imprevisível, da criação: o acontecimento. Ainda que, por estas linhas, tenhamos optado por determo-nos na singularidade de um só dispositivo, o da moda, é fato que estamos imersos a muitos outros, característica da sociedade contemporânea. No interior desses dispositivos em que os enunciados se cruzam e se confrontam, sejam linguísticos, imagéticos ou sincréticos, o campo do olhar e do dizer vai esculpindo o alicerce dos saberes e dos poderes, "sensibilidade onde vai poder se inventar e desenvolver" (COURTINE, 2013, p. 137) princípios, normas, regras, padrões.

\section{EFEITOS DE ARREMATE}

Guiados pelos pensamentos foucaultianos, ao longo desta escrita mergulhamos nas costuras que tecem as relações de poder e saber da moda, as quais produzem sentidos sobre os corpos que extrapolam a construção do ideal corpóreo feminino.

A moda, enquanto um dispositivo de controle, ao se apropriar, nas malhas do seu discurso, do corpo dito e visto como gordo o faz em resposta à urgência social da diversidade. Contudo, ao discursivizar esse corpo, numa perspectiva de normalização, objetiva o sujeito mulher, subjetivada como gorda, por meio de apelos morais que incidem diretamente sobre o corpo na garantia de inclusão, ou melhor, de um efeito de inclusão, em espaços de visibilidade então destinados àquele subjetivado como magro, logo, beneficiário de moda. Assim, para compreender o discurso da moda circunscrito ao corpo desviante gordo, cumpre citar como uma de suas estratégias fundamentais a oferta de uma espécie de contrato, como um acordo estabelecido no dispositivo de segurança entre o Estado e o cidadão.

Das cláusulas desse contrato em questão, cabe ao sujeito um cuidado de si por condutas modelares que o enquadram nos parâmetros da normalidade. É preciso, pelas roupas, esconder a opulência da carne, pois, se há corpos desviantes do padrão estético magro e longilíneo, há também diversas maneiras para que todos nele sejam enquadrados.

Bordejando a moda, lançamos nosso gesto de interpretação, e a partir do lugar que ocupamos como analistas do discurso, ao traçarmos um percurso, delimitar lugares e caminhos, conclui-se que, em um movimento estratégico no jogo discursivo, o dispositivo da moda, ao enunciar um corpo desviante de uma ordem corpórea pré-estabelecida no jogo dicotômico belo/feio, enuncia, de modo concomitante, um discurso do corpo perfeito que fala na/para a moda, o subjetivado magro, interditando na retomada da ordem de (in)visibilidade por meio de seus exercícios de poder àquele que falta, que falha aos padrões de normalidade, o corpo feminino subjetivado como gordo.

Logo, diante das vertiginosas transformações em curso na sociedade pós-moderna, acreditamos que as discussões aqui germinadas possam contribuir no deslocar de sentidos já cristalizados, suscitando debates e reflexões que colaborem na problematização sobre a 
formação de estereótipos pela moda, assim como para a construção de uma visão crítica, de um espaço de ruptura aberto a possibilidades de interpretar e, porque não, acolher (dando voz e vez) à multiplicidade corpórea nesse deslizante e movediço terreno estético.

\section{REFERÊNCIAS BIBLIOGRÁFICAS}

AGAMBEN, G. Homo sacer: o poder soberano e a vida nua. Belo Horizonte: Editora UFMG, 2005.

ALBUQUERQUE JÚNIOR, D. M. Diz positivo: entre o castor e a aranha. In: FERNANDES JÚNIOR, A.; SOUSA, K. M. Dispositivos de poder em Foucault: práticas e discursos da atualidade. Goiânia: Gráfica UFG, 2017. p. 5-9.

CALANCA, D. História social da moda. Tradução de Renato Ambrósio. São Paulo: Editora Senac São Paulo, 2011.

CASTRO, A. L. Culto ao corpo e sociedade: mídia, estilos de vida e cultura de consumo. São Paulo: AnnaBlume, 2007.

COURTINE, J. J. Decifrar o corpo: pensar com Foucault. Tradução de Francisco Morás. Petrópolis, RJ: Vozes, 2013.

DELEUZE, G. Conversações. 2. ed. São Paulo: Editora 34, 2010.

FOUCAULT, M. A arqueologia do saber. Tradução de Luiz Felipe Baeta Neves. 3. ed. Rio de Janeiro: Forense - Universitária, 1987.

FOUCAULT, M. Microfísica do poder. Por uma genealogia do poder. 13. ed. Rio de Janeiro: Graal, 1998.

FOUCAULT, M. A ordem do discurso. 12. ed. Tradução de Laura Fraga de Almeida Sampaio. São Paulo: Edições Loyola, 2000.

FOUCAULT, M. Segurança, território, população: curso dado no Collège de France. 1. ed. São Paulo: Martins Fontes, 2008.

FOUCAULT, M. Vigiar e punir: nascimento da prisão. 36. ed. Tradução de Raquel Ramalhete. Petrópolis, RJ: Vozes, 2009.

FOUCAULT, M. Sobre a história da sexualidade. Microfísica do poder. Rio de Janeiro: Edições Graal, 2011. p. 243-276.

GREGOLIN, M. R. Foucault e Pêcheux na análise do discurso: diálogos e duelos. 2. ed. São Carlos, SP: Claraluz, 2006.

KATZ, H. Para ser contemporâneo da biopolítica: corpo, moda, trevas e luz. In: MESQUITA, C.; CASTILHO, K. (Org.). Corpo, moda e ética: pistas para uma reflexão de valores. São Paulo: Estação das Letras Cores, 2011. 
LIPOVETSKY, G. O. O império do efêmero: a moda e seu destino na sociedade moderna. Tradução de Maria Lúcia Machado. São Paulo: Companhia das letras, 2009.

MARIANO, M. L. V. Da construção à desconstrução: a modelagem como recurso criativo no design de moda. 2011. 139 f. Dissertação (Mestrado em Design) - Universidade Anhembi Morumbi, São Paulo.

MENDES, C. L. O Corpo em Foucault: superfície de disciplinamento e governo. Revista de Ciências Humanas. Florianópolis: EDUFSCar, n. 39, abr. 2006, p. 167-181.

NOVAES, J.V. Com que corpo eu vou? Sociabilidade e usos do corpo nas mulheres das camadas altas e populares. Editora PUC- Rio, 2010.

Revista Moda Moldes: Especial Plus Size. São Paulo: On Line Editora, ano 1, n. 2, maio 2010.66 p. Revista Moda Moldes: Especial Plus Size. São Paulo: On Line Editora, ano 4, n. 21, abril 2016. $66 \mathrm{p}$.

SARGENTINI, V. M. O. Dispositivo: um aporte metodológico para o estudo do discurso. In: SOUZA, K. M.; PAIXÃO, H. P. (Org.). Dispositivos de poder/saber em Michel Foucault: biopolítica, corpo e subjetividade. São Paulo: Intermeios; Goiânia: UFG, 2015.

Recebido para publicação em: 13 maio 2020. Aceito para publicação em: 11 ago. 2020. 